\begin{tabular}{|c|c|c|c|}
\hline Article Info & REASEARCH ARTICLE & ARAŞTIRMA MAKALESİ & \\
\hline Title of Article & \multicolumn{2}{|c|}{$\begin{array}{l}\text { The Post Occupancy Evaluation, Filyos Coast Park } \\
\text { Example }\end{array}$} & \\
\hline $\begin{array}{l}\text { Corresponding } \\
\text { Author }\end{array}$ & \multicolumn{2}{|c|}{$\begin{array}{l}\text { Doç. Dr. Sima POUYA } \\
\text { İnönü Üniversitesi, Güzel Sanatlar ve Tasarım Fakültesi, Peyzaj Mimarlığı Bölümü, } \\
\text { Malatya. } \underline{\text { sima.pouya@inonu.edu.tr }}\end{array}$} & \\
\hline $\begin{array}{l}\text { Received Date } \\
\text { Accepted Date }\end{array}$ & \multicolumn{2}{|l|}{$\begin{array}{l}14.09 .2020 \\
13.01 .2021\end{array}$} & \\
\hline Author / Authors & $\begin{array}{l}\text { Sima POUYA } \\
\text { Buğrahan TOPALOĞLU }\end{array}$ & $\begin{array}{l}\text { ORCID: 0000-0001-6419-1756 } \\
\text { ORCID: 0000-0002-1581-9567 }\end{array}$ & \\
\hline How to Cite & \multicolumn{2}{|c|}{$\begin{array}{l}\text { Pouya, S. and Topaloğlu, B. (2021). The Post Occupancy Evaluation, Filyos Coast } \\
\text { Park Example, Kent Akademisi, Volume, 14, Issue 1, Pages, 20-28. }\end{array}$} & $\begin{array}{l}\text { Kent Akademisi } \\
\text { Urban Academy }\end{array}$ \\
\hline
\end{tabular}

\title{
Kullanım Sonrası Değerlendirme Metodu, Filyos Sahil Parkı Örneği
}

\begin{abstract}
:
It has been explained by many researchers that today's urban parks contribute to the physical and mental recovery of people. While planning these areas, it passes through the design, application and useing stages respectively. However, while the design and implementation stages of these areas are emphasized a lot; usage and post occupancy evaluation stages are ignored. Users play an important role in the usage phase. In fact, there are no users (children, elderly, young people, etc.) as the most time-consuming in the planning stages, creates a major shortcoming. The Post Occupancy Evaluation (POE) is a method created for the design and implementation process of the area with considering the thoughts and requests of its users. This study was carried out in Filyos Beach Park in Zonguldak to evaluate user satisfaction and to find and eliminate the park's deficiencies in terms of usage. In the study area, observation and survey work was carried out using the method of POE. The suggestions brought according to the results of the study; the evaluation of especially public transportation vehicles, reproduction of usage variety and placing information signs where necessary.
\end{abstract}

KEYWORDS: Urban areas, Open green areas, User, Post-Use Evaluation, Landscape design.

\section{ÖZ:}

Günümüzdeki kentsel parkların insanların fiziksel ve ruhsal iyileşmelerine katkı sağladığı birçok araştırmacı tarafından açıklanmıştır. Bu alanlar planlanırken sırasıyla tasarım, uygulama, ve kullanım aşamaların yapılması gerekmektedir. Ancak bu alanların tasarım ve uygulama aşamaları üzerinde çok durulurken; kullanım ve kullanım sonrası değerlendirme aşamaları genellikle ihmal edilmektedir. Bu da alanda asıl önemli olan kullanıcı ihtiyaçlarının geri planda kalmasına sebep olmaktadır. Aslında mekanda en çok zaman geçiren kullanıcıların (çocuklar, yaşlılar, gençler vb.) planlama aşamalarında olmamaları büyük bir eksiklik yaratmaktadır. Kullanım Sonrası Değerlendirme Yöntemi (KSD), kullanıcılarının düşüncelerini ve isteklerini de göz önüne alınarak alanın tasarım ve uygulama sürecinin yapılması için oluşturulmuş bir yöntemdir. Bu çalışma Zonguldak’ta bulunan Filyos Sahil Parkı'nda kullanıcı memnuniyetinin

${ }^{1}$ Assoc. Prof. Dr. Sima POUYA, Inönü University, School of Fine Arts and Design, Department of Landscape Architecture, Landscape Design Subdivision, 44210-44000 Battalgazi, Malatya, sima.pouya@inonu.edu.tr

${ }^{2}$ Buğrahan TOPALOĞLU (Master student). Inönü University, School of Fine Arts and Design, Department of Landscape Architecture, Landscape Design Subdivision, 44210-44000 Battalgazi, Malatya, topaloglubugrahan@gmail.com. 
değerlendirilmesi ve kullanım açısından parkın eksiklerinin bulunması ve giderilmesi amacı ile yapılmıştır. Çalışma alanında KSD metodu kullanılarak gözlem tekniği ve anket çalışması gerçekleştirilmiş̧tir. Çalışmanın sonuçlarına göre getirilen öneriler; alana özellikle toplu ulaşım araçların değerlendirilmesi, kullanım çeşitliğinin çoğaltılması ve gereken yerlerde bilgilendirme tabelaları yerleştirilmesi olmuştur.

ANAHTAR KELIMELER: Kentsel alanlar, Açık yeşil alanlar, Kullanıcı, Kullanım sonrası değerlendirme, Peyzaj tasarımı.

\section{"Kullanım Sonrası Değerlendirme Metodu, Filyos Sahil Parkı Örneği”"}

\section{GİRIŞ:}

Kentler geçmişten bu yana sürekli değişip gelişmişlerdir. Günümüzde de bu değişim ve gelişim devam etmektedir. Kentler, içindeki toplumu şekillendirmiş ve aynı şekilde toplumdaki her bireyden etkilenerek değişmiş ve kent kimliğine geçmiştir (Erikci Çelik ve Zorer Gedik, 2019).

Ayrıca kentin kimliği kentlerin tanınmasını ve ayırt edilmesini kolaylaştırmaktadır. Kentler, insanların davranışını ve ilişkilerini, bireylerin zihnindeki çağrışımları doğrudan etkiler. İnsanlara farklı olanla karşılaşma, tanıma ve etkileşim içinde olma fırsatını sağlayan kentler, bu firsatı bireylere sunmaktadır. Kentsel alanlarda ortaya çıkan en güçlü unsur şüphesiz ki ortak kullanılan alanlardır. Özellikle açık alanlar, kentlerde yaşayanların en çok yararlandığı alanlardandır (Şimşek vd. 2011). Açık alanlar, bireylerin yaşantısını devam ettirdiği, üzerine inşa yapılmamış, kapalı mekânların dışında, doğal durumda, konut dışı çeşitli etkinlik amaçları için ayrılmış kent parçalarıodır. Kentsel açık alanlar, herkese aittir. Özel olarak kimseye ait olmayan, sosyal amaçlar için pek çok insanın kullanabildiği mekanlar topluma ait olma ve ortak kullanıma açık olma gibi iki özelliği vardır. Bu açık alanların bir kısmı tamamlayıcı alanlar (sokaklar, meydanlar), bir diğer kısmı da işlevsel alanlardır (parklar gibi) (Şimşek vd. 2011).

Kentsel açık alanlar inşa edilip bir süre kullanıldıktan sonra, kullanıcıların alanları nasıl algıladıkları, ne amaçla kullandıkları, ne tür etkileşimlerde bulundukları ve alanların söz konusu etkileşimlere ve sosyal eylemlere fiziksel açıdan ne ölçüde imkân verdiği gibi konular düzenli bir şekilde değerlendirilmelidir. Bu değerlendirme sonucu elde edilen bilgiler gelecekteki tasarımların daha başarılı olması için plancılara kaynak oluşturabilir (Uzgören ve Erdönmez 2017; Akad, 2007; Pouya vd, 2017; Pouya ve Demirel, 2018; Pouya, 2019).

Bu çalışma Zonguldak'ta bulunan Filyos Sahil Parkı'nda kullanıcı memnuniyetini değerlendirmek ve kullanım açısından parkın eksiklerinin bulunması ve giderilmesi amacı ile yapılmıştır.

\subsection{Kullanım Sonrası Değerlendirme}

Kullanım Sonrası Değerlendirme (KSD) yöntemi alanın planlayıcısına, sahibine ve alanı kullananlara önemli veriler sağlar. Alandan istenilen gereksinimler tespit edilerek sonuçlar ortaya konulur. Ortaya çıkan sonuçlara göre de kullanıcılara yönelik öneriler geliştirilebilir (Evrim, 2010).

KSD yöntemi; incelenen mekanın planlamasındaki tasarımın değerlendirilmesi, kullanıcı gereksinimlerinin gözlemlenmesi ve ortaya çıkan sonuç ürünün değerlendirilmesine dayanmaktadır. Bu yöntem uygulandığında, tasarım ve ürün karşılaştırılarak tasarımın güçlü ve zayıf yönleri belirlenir. Bu belirlemenin sonuçları yeni tasarımlara veri olarak aktarılır, mevcut çevrelerdeki sorunların çözümü için de geri dönüş olarak sürece dâhil edilir (Evrim, 2010). KSD, görüşme, gözlem ve başka metotlar kullanarak, tasarlanan çevrelerin iyi anlaşılmasını sağlayan şeyleri doğru olarak keşfedebilme sürecidir. KSD, inşa edilip ve bir süre kullanılmış yapıları sistemli ve bir biçimde değerlendirme olarak tanımlar ve bina kullanıcılarını Kullanım Sürecinde Değerlendirmenin odağında görür (Tablo 1) (Onat ve Dinç, 1998). 
Tablo 1. KSD’deki araştırma teknikleri (Onat ve Dinç 1998).

\begin{tabular}{|c|c|c|}
\hline Tekniğin Adı & Tekniğin işleyişi & Tekniğin Ana Amacı \\
\hline $\begin{array}{l}\text { Literatür Araştırması } \\
\text { Yapmak }\end{array}$ & Yazılı ve çizili kaynaklara ulaşma & $\begin{array}{l}\text { Önceki araştırma, ve eleştiri } \\
\text { çalışmalarından yararlanmak. }\end{array}$ \\
\hline Gözlem Yapmak & Saptamalar yapmak & $\begin{array}{c}\text { Kendine özgü nitelik, olgu ve olayları fark } \\
\text { etmek }\end{array}$ \\
\hline $\begin{array}{l}\text { Görüşmelerin } \\
\text { gerçekleştirmesi }\end{array}$ & Katılımcılarla görüşme yapmak & $\begin{array}{l}\text { Katılımcıların yapılan uygulamalarla ilgili } \\
\text { özel görüşlerini almak }\end{array}$ \\
\hline Fotoğraf Çekmek & $\begin{array}{l}\text { Problem alanlarının doğru zamanda } \\
\text { saptanması }\end{array}$ & $\begin{array}{l}\text { Kanıları güçlendirme, örnekleme, } \\
\text { doğrulama/ yanlış lama, kanıtlama }\end{array}$ \\
\hline Grup süreçleri & $\begin{array}{l}\text { Katılımcıların bir arada kendilerini } \\
\text { ifade etmelerini sağlamak }\end{array}$ & Katılımcıyı etkin kılmak \\
\hline Oyun & $\begin{array}{c}\text { "şayet..." senaryoları hazırlayarak } \\
\text { katılımcılarla çalışmak }\end{array}$ & $\begin{array}{l}\text { Öncelikleri belirlemek ve tasarım sürecini } \\
\text { katılımcıya aktarabilmek }\end{array}$ \\
\hline $\begin{array}{l}\text { Günlükler ve Zaman } \\
\text { Ölçümleri }\end{array}$ & $\begin{array}{l}\text { Eylemlerin belli zaman } \\
\text { aralıkları ile kaydedilmesi }\end{array}$ & $\begin{array}{l}\text { Eylem dizgelerinin, akışların ve bütünün } \\
\text { ele geçirilmesi }\end{array}$ \\
\hline Durum Çalışması & $\begin{array}{l}\text { Konu ile ilgili örneklerin } \\
\text { derinlemesine incelenmesi }\end{array}$ & Gerçek yaşam ile ilgili detaylı bilgi almak \\
\hline Benzetmeler Yapmak & $\begin{array}{l}\text { Katılımcıların bilgilerine } \\
\text { başvurmak }\end{array}$ & Yönelim ve eğilimlerin belirlenmesi \\
\hline $\begin{array}{c}\text { Soru Formları ve } \\
\text { Anketler Düzenlemek }\end{array}$ & Çok kişinin görüşünü alma & Genel ve özel eğilimlerin saptanması \\
\hline Deneyler & $\begin{array}{c}\text { Farklı koşullarda ve durumlarda } \\
\text { kullanıcıların tepkilerini öğrenmek }\end{array}$ & Öngörülen yararlılığın tahmini \\
\hline Maketler & $\begin{array}{l}\text { Özel mekanların maketlerinin } \\
\text { yapılması }\end{array}$ & $\begin{array}{l}\text { Özel mekanlar için isabetli yatırımları } \\
\text { gerçekleştirmek }\end{array}$ \\
\hline $\begin{array}{l}\text { Tasarım Kayıtları } \\
\text { Oluşturmak }\end{array}$ & $\begin{array}{c}\text { Tasarım sürecindeki tüm aşamaların } \\
\text { kaydının yapılması }\end{array}$ & Tasarım kontrolü. \\
\hline
\end{tabular}

KSD yönteminin temel amaçları;

- Mekanda ortaya çıkabilecek acil durum sorunları için veri elde etmek,

- Mekanı kullananların karşılaştıkları fakat yapım sırasında fark edilmeyen problemlerin çözümüne destek vermek,

- Mekanın kullanımı sırasında, kullanıcı ile çevre dengesinin kurulmasını sağlamak,

- Mekan ile ilgili durumları veri olarak kabul edip aynı tip mekânlar için çözümlemeye örnek teşkil etmek,

- KSD mekânların genelleştirilerek var olan tasarım ölçütlerini yenilemek ve ilgili alanda bilimsel yayınlar hazırlamak için kullanılır (Presier ve Vischer, 2005).

KSD Süreç Model'inde tasarımlar, planlama, uygulama ve yönetim olarak üç aşama içerir. Planlama aşaması; çalışmanın kapsamını belirlemek, literatür araştırması yapmak, çalışma için uygun verileri toplamak, analiz yöntemleri ve ekipmanları belirlemek, iş tanımları ve süre planlamasının belirlenmesini içerir (Kuyucu ve Vatan, 2017; Preiser vd, 2015; Zimring ve Reizenstein, 1980).

Yönetim aşaması; sahada veri toplanma ve bu verilerin analiz edilmesinden oluşur. Uygulama aşaması mekana ait olumlu - olumsuz özelliklerin ve problemlerin belirlenmesi ve çözüm önerilerinin geliştirilmesi, yeni yapılacak alanlar için veri sağlaması gibi amaçlara yönelik değerlendirme ve belirlemelerin bir yazılı kaynak olarak oluşturulmasıdır. Kullanım sonrası değerlendirme çalışmalarında sıkça rastlanan değerlendirme kavramındaki değer, karşıladığı ihtiyaca göre bir nitelik anlamına gelmektedir. Değerlendirme; bir şeyin değerini saptamak, sınamak, yargılamak olarak da 
özetlenebilir. Değer kavramı; estetik bir gereksinim ise estetik değer, ekonomik bir gereksinim ise ekonomik değer, kullanıma yönelik ise işlevsel değer, teknik bir gereksinim ise de teknik değer olarak adlandırılır (Karagenç, 2002).

KSD mekanın önceden belirlenen amaca uygun olarak kullanıp kullanılmadığını, kullanıııların ne gibi aktiviteler için bu alanları kullandığını, kimlerin, hangi aktiviteleri, hangi sıklıkta, hangi alanlarda, gerçekleştirdiğini, alanların kullanıcı gereksinim ve isteklerine cevap verip vermediğini belirlemekte kullanılır. Böylece KSD`den elde edilen bulgular, hem mevcut alanlarda yapılacak olan değiş̧iklileri, hem de bundan sonra düzenlenecek olan benzer kamusal açık alanlarda kullanıcı istek ve ihtiyaçlarını esas alan tasarımların yapılmasını sağlar.

KSD, tasarımların beklenen etkilerini anlamayı, tamamlanan tasarımları incelemeyi, bina aktivitelerini ve bina yönetimini desteklemeyi amaçlayan uygulamaların bir parçasıdır. Ayrıca KSD, çevresel psikoloji, planlama ve davranış çalışmalarına da hizmet eder (Onat ve Dinç, 1998).

\subsection{Davranış Haritalaması}

Fiziksel çevrenin özelliklerine göre insanların davranışlarını sistematik bir şekilde gözlemleyip araştıran bilim dalına davranış haritalama denir. $\mathrm{Bu}$ yöntem ile araştırmacılar, bir harita üzerinde uygun tablolarla belirli bir çalışma alanı içinde bireylerin pozisyonlarını, fiziki aktiviteleri, kişinin cinsiyeti, yaşı, sosyal iletişim durumları gibi birçok özelliğini kaydetmektedirler. Araştırmacılar binalarda, açık alanlarda, müzelerde, hayvanat bahçelerinde, konutlarda, hastanelerde, alışveriş merkezlerinde insan faaliyetlerini incelemek için davranışsal haritalama yöntemini kullanmışlardır (McKenzie vd.2000).

Davranış haritaları, daha önceden tanımlanan davranış kodlarının harita üzerine işlenmesi ile hazırlanır. Davranış kodları, davranış haritalarında analiz birimleri olarak düşünülebilir. Davranış kodlarına örnek olarak, o mekanda yapılması olası aktiviteler (oturma, yürüme, sohbet, beslenme ) gösterilebilir. Haritalama yapan araştırmacılar, önceden tanımlanmış davranış kodları ve belirli zaman süresince bireylerin hareketlerini kaydedip haritalarlar. Yapılan gözlemler bireylerden habersiz gerçekleştirilmelidir. Gözlemciler, bireyin tanımlanan alandaki eylemlerini gözlem yolu ile doğrudan veya gözlem cihazları (kamera, gps vb.) aracılı̆̆ı ile takip edebilmektedir. Yer merkezli davranış haritaları, bireylerin belirli bir yer ve zaman içindeki davranışlarını gösterir (URL 1).

$\mathrm{Bu}$ haritalar, bir yerin kullanıcıları ile bu yerdeki faaliyet türlerinin ilişkilendirilmesi, zamansal ve mekansal olarak analiz edilmesini amaçlamaktadır (URL 1). Davranış haritalarının, mimar, tasarımcı, çevre ve davranış çalışmaları yapan akademisyenler tarafından sıklıkla kullanıldığı görülmüştür. Gözlemlerin gerçekleştĭgi zamanın seçimi önemlidir. Çünkü bir yer farklı saatlerde farklı kişiler tarafından farklı şekilde kullanılabilir.

\section{Materyal ve Metod}

\subsection{Materyal}

Çalışma alanı olarak belirlenen Filyos Sahil Parkı 2011 yılında Filyos Belediyesi tarafından sahil düzenleme çalışmaları kapsamında yapılmıştır. Park toplam $11.900 \mathrm{~m}^{2}$ alana sahiptir. Park içerisinde 3 adet kafe, 2 adet çocuk oyun alanı, 18 adet bank, 8 adet çardak ve yürüyüş yolları bulunmaktadır (Şekil 1 ve 2).

Zonguldak'ın Çaycuma ilçesine bağlı Filyos Beldesi M.Ö. 7. yüzyılda kurulmuştur. Tarihi boyunca değişik isimlerle (Tios, Tieion, Tianon, Tium) anılan kent tarihi boyunca siyasi güç oluşturamayan ve Ereğli ile Amasra ilçesinin gölgesinde kalmıştır. Zonguldak ili Çaycuma İlçesi Filyos Beldesi, Billaios (Billaeus-Filyos) nehrinin Karadeniz'e döküldüğü alanda kurulmuştur. İlk Çağlarda nehrin adından dolayı Billaios adıyla biliniyordu. Bu sözcük paila ( $\mathrm{Su}$ geçidi) sözcüğüne (Tireios) takısının eklenmesi ile Pailaios, Billaios biçimlerinde kullanılmış Filyos adı da muhtemelen bu sözcükleri zamanla ses değişimine uğramasından ortaya çıkmıştır. Kent, Bizans döneminde önemli bir dini merkez olmuştur. Selçuklu ve Osmanlı dönemlerinde ise önemini yitirmiş ve küçük bir balıkçı köyüne dönüştürülmüştür. günümüzde Filyos Beldesinin bulunduğu yerde Roma, Bizans ve orta çağ dönemlerinden kalan Kale, sahil surları, su kemeri, tiyatro, savunma kulesi ve çeşitli mezarlar bulunmaktadır (URL 2). 

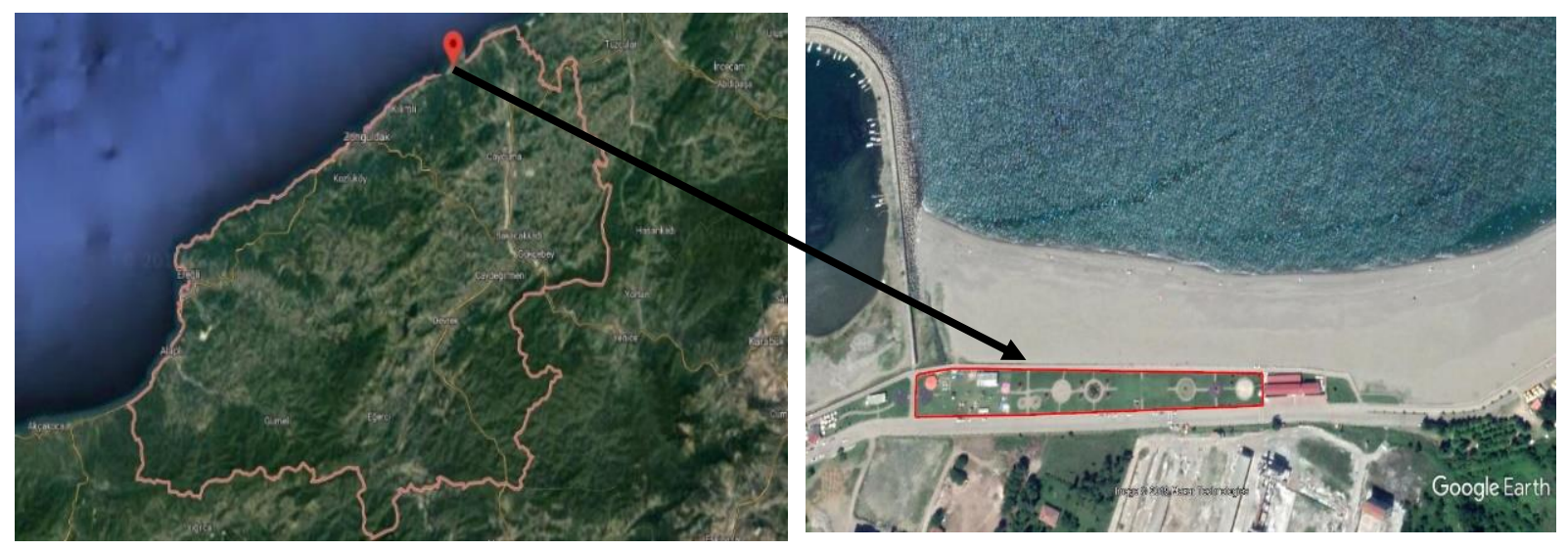

Şekil 1. Çalışma alanın konumu (Google Earth sitesinden alınan haritalar)
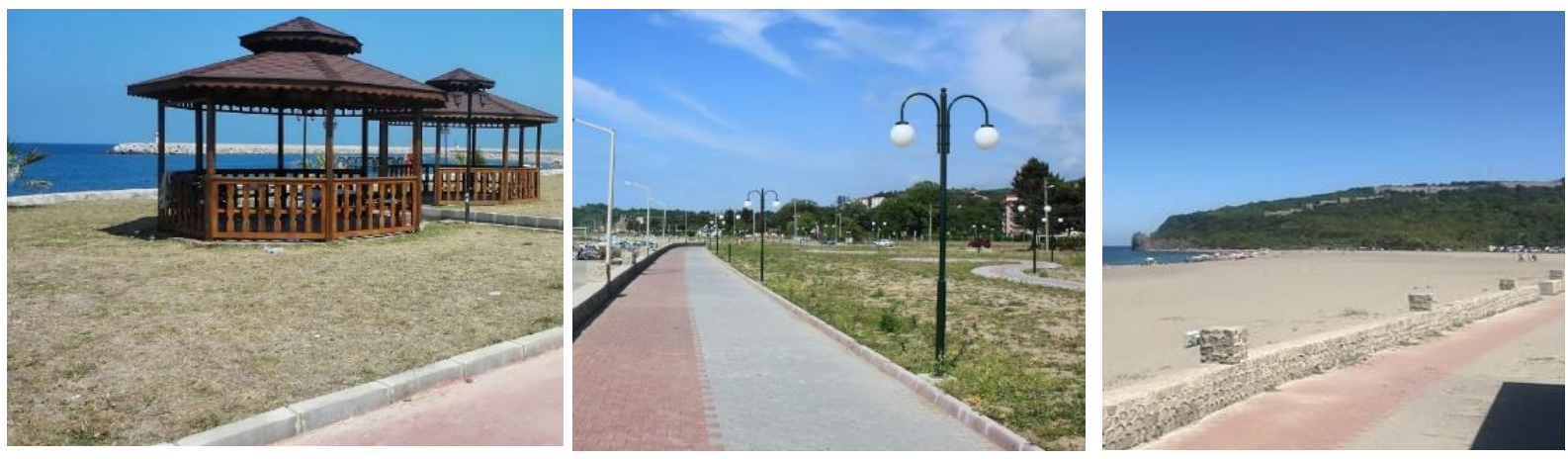

Şekil 2. Çalışma alanından çekilen resimler

\subsection{Metot}

Çalışma alanı olarak belirlenen Filyos Sahil Parkı alanında olumlu ve olumsuz yönlerinin araştırılması ve bu alanın kullanım açısından değerlendirilmesi için KSD metodu kullanılmıştır. Araştırma alanına gelen ziyaretçilerin hangi saatlerde ve hangi amaçla alanı kullandıklarını açılamak ve ayrıca bu bireylerin daha çok hangi aktiviteleri yapmak istediklerini tespit etmek için gözlem çalışması yapılmıştır.

Alana gelen ziyaretçilerin eylem ve davranışlarını farklı günlerde ve saatlerde gözlemlenmek amacıyla bu çalışma altı farklı günde, farklı saatlerde ve farklı hava koşullarında yapılmıştır (Tablo 2). Gözlem türü yapılandırılmamış gözlem ve yerinde gözlem olmuştur. Gözlem çalışmasından elde edilen bulguları daha net bir şekilde algılamak amacıyla yapılan gözlemlerler sonucunda alanın durum haritası ve davranış haritası oluşturulmuştur. Haritaların yapımında ArcGIS. 10.5 programı kullanılmıştır.

Yapılan yerinde gözlemler ile ulaşım durumu, alanın kullanım saatleri ve kullanım süreleri, alanın ne amaçla kullanıldığı gibi kriterler belirlenmiş ve bu kriterler ışı̆ıında anket soruları oluşturulmuştur. Alanda anket yapabilecek kişilerin az olması nedeniyle çalışmada ancak 50 kişiye anket çalışması yapılmıştır. Toplam 10 sorudan oluşan anketin amacı ise alanın kullanıcı memnuniyetini incelemek ve işlevsel ve estetik değerlendirilmesi olmuştur. Farklı grup bireylere anket yaptırmak amacıyla anketler haftanın farklı günlerinde farlı saatlerde uygulanmıştır. Üç bölümden oluşan bu ankette kullanıcıların demografik özelliklerine (yaş, cinsiyet vb.), kullanıcıların mekânsal davranışlarına (kullanım süresi, kullanım sıklı̆̆ı vb.), mekânın kullanım amacı ve mekânın eksiklilerine ilişkin veri toplanmıştır. 


\section{Bulgular}

\subsection{Gözlemler Sonucunda Elde Edilen Bulgular}

Yapılandırılmamış gözlem çalışmasında alandaki bireylerin davranışlarını ve yaptıkları etkinlikleri ve ilgilendikleri alanları kayda alıp ve gözlem formunda not etmiştir. Daha sonra yazılı notlar incelenmiş ve sözlem sırasında gerçekleşen eylemler çıkarılmıştır. Tablo 2'de gözlem formundan elde edilen veriler açılanmıştır.

Gözlem sırasında gerçekleşen eylemler sırasıyla; çim alanlarında, tasarlanan oturma banklarında veya çardaklarda, kafelerde ve sahildeki yollarda oturma ve dinlenme, yürüyüş yapma ve çocuk oyun alanını kullanma eylemleri olmuştur. Tablo 2'ye göre hava durumuna bağlı olarak kişilerin katıldığı aktivitelerinin değiştiği, yağmurlu ve bulutlu havalarda kullanıcıların alandaki bulunan kafeleri ve güneşli havalarda ise sahili ve açık alandaki oturma bankları tercih ettikleri tespit edilmiştir. Günün her saatinde çalışma alanındaki kafelerin tercih edildiği, çocuk oyun alanlarının ise öğle saatlerinde daha fazla kullanıldığı açıklanmıştır. Havanın sıcak olduğu günlerde çimlerde oturma ve yollarda yürüyüş yapanların oranının yükseldiği tespit edilmiştir.

Tablo 2. Filyos Sahil Parkı, gözlem sırasında gerçekleşen eylemler

\begin{tabular}{|c|c|c|c|c|c|c|c|}
\hline \multirow[t]{2}{*}{ Gözlem saati ve günü } & \multirow[t]{2}{*}{ Hava Durumu } & \multicolumn{6}{|c|}{ Gözlemlenen Eylemler } \\
\hline & & $\begin{array}{l}\text { Çimde } \\
\text { Oturma }\end{array}$ & $\begin{array}{l}\text { Bankta/ } \\
\text { çardakta } \\
\text { Oturma }\end{array}$ & $\begin{array}{l}\text { Sahilde } \\
\text { Oturma }\end{array}$ & Kafe & $\begin{array}{l}\text { Koşu / } \\
\text { Yürüyüş }\end{array}$ & $\begin{array}{l}\text { Çocuk } \\
\text { Oyun } \\
\text { Alanı }\end{array}$ \\
\hline $\begin{array}{l}\text { 01.11.2019-Cuma } \\
\text { 11:00-12:30 }\end{array}$ & Yağmurlu- $8^{\circ} \mathrm{C}$ & 0 & 1 & 0 & 10 & 2 & 0 \\
\hline $\begin{array}{l}\text { 03.11.2019-Pazar } \\
\text { 10:30-12:00 }\end{array}$ & Güneşli-18 ${ }^{\circ} \mathrm{C}$ & 6 & 4 & 10 & 7 & 5 & 10 \\
\hline $\begin{array}{l}\text { 03.11.2019-Pazar } \\
\text { 16:00-18:00 }\end{array}$ & Az Bulutlu- $14{ }^{\circ} \mathrm{C}$ & 3 & 3 & 7 & 5 & 3 & 6 \\
\hline $\begin{array}{l}\text { 06.11.2019-Perşembe } \\
\text { 12:00-13:00 }\end{array}$ & Bulutlu- $9{ }^{\circ} \mathrm{C}$ & 0 & 4 & 3 & 8 & 1 & 2 \\
\hline $\begin{array}{l}\text { 10.11.2019-Pazar } \\
\text { 08:00-10:00 }\end{array}$ & Güneşli-26 ${ }^{\circ} \mathrm{C}$ & 5 & 2 & 5 & 3 & 4 & 5 \\
\hline $\begin{array}{l}\text { 10.11.2019-Pazar } \\
\text { 13:30-14:30 }\end{array}$ & Güneşli- $18^{\circ} \mathrm{C}$ & 7 & 8 & 12 & 7 & 5 & 9 \\
\hline $\begin{array}{l}\text { 12.11.2019-Salı } \\
18: 00-19: 30\end{array}$ & Yağmurlu- $5{ }^{\circ} \mathrm{C}$ & 0 & 0 & 0 & 6 & 1 & 0 \\
\hline $\begin{array}{l}\text { 16.11.2019-Cumartesi } \\
14: 00-15: 00\end{array}$ & Az Bulutlu- $12{ }^{\circ} \mathrm{C}$ & 4 & 2 & 5 & 8 & 3 & 6 \\
\hline $\begin{array}{l}\text { 16.11.2019-Cumartesi } \\
\text { 17:30-18:00 }\end{array}$ & Az Bulutlu- $12{ }^{\circ} \mathrm{C}$ & 2 & 2 & 5 & 7 & 1 & 2 \\
\hline
\end{tabular}

\subsection{Filyos Sahil Parkın'a Ait Davranış ve Durum Haritası}

Yapılan gözlemlerler sonucunda parkın durum haritası ve davranış haritası oluşturulmuştur. Parkın genel vaziyeti sayısallaştırılmış, sayısal görüntü üzerine gözlemlerden elde edilen veriler eklenerek haritalar oluşturulmuştur. Gözlem sonuçlarından oluşturulan davranış haritasına göre kullanıcıların çoğunluk sırasıyla kafeleri, çardaklar, bankları ve yürüyüş yolunu tercih etmişlerdir. Oyun alanları ve parktaki kullanılmayan boş alanları ise tercih eden olmamıştır (Şekil $3)$. 

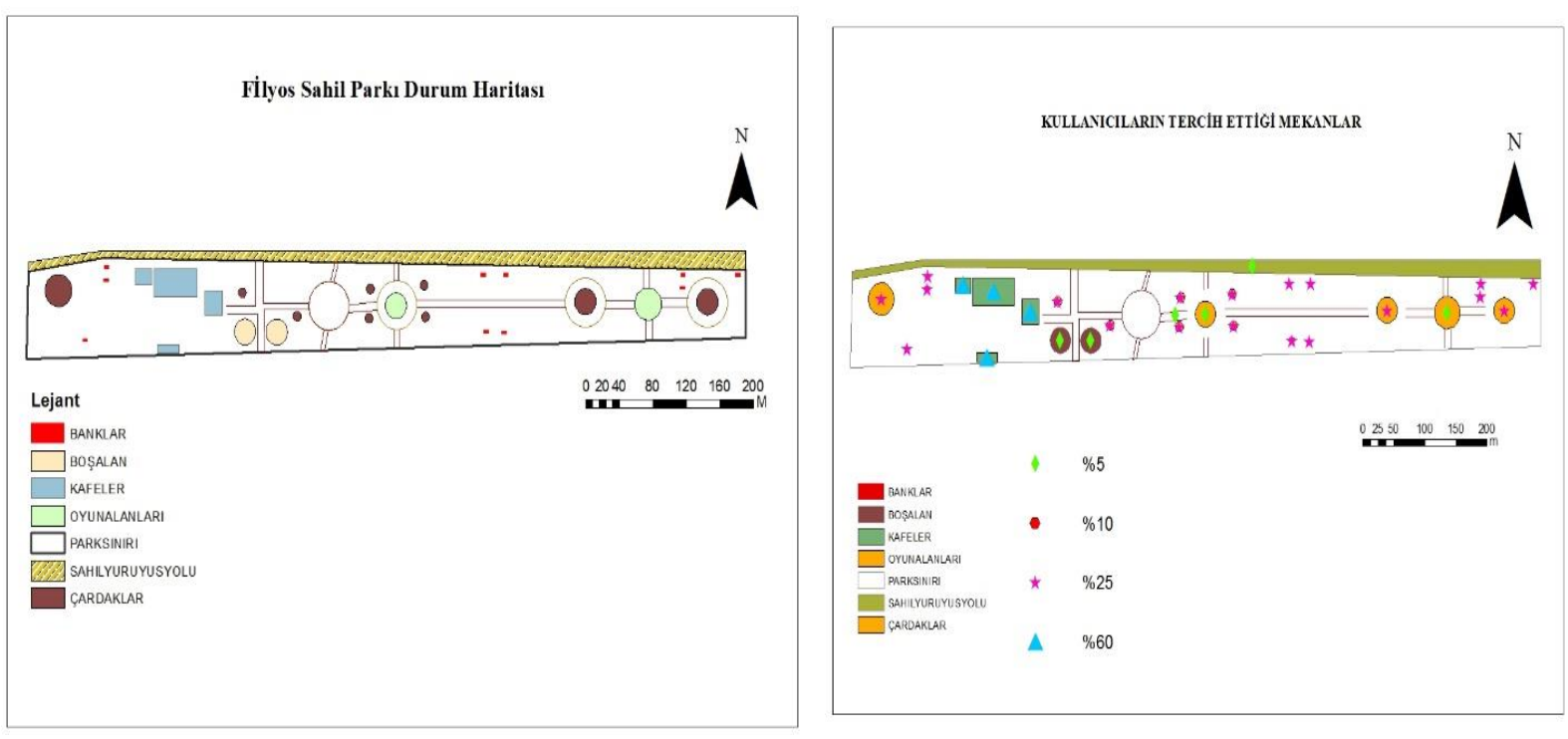

Şekil 3. Çalışma alanında gerçekleşen gözlem çalışması sonuçlarına göre iki farklı harita oluşmuştur. Filyos Sahil Parkı'na ait durum haritası (soldaki görünüm) ve Filyos Sahil Parkı'na ait davranış haritası (sağdaki görünüm).

\subsection{Anket Çalışmasından Elde Edilen Bulgular}

Dört farklı günde park kullanıcıları ile yüz yüze anket çalışması yapılmıştır. Seçilen kişilerde her hangi bir kriter aramadın sadece göllü olarak anket sorularına cevap vermeleri istenmiştir. Alanda anket yapabilecek kişilerin az olması nedeniyle çalışmada ancak 50 kişiye anket çalışması yapılmıştır.

Anket çalışmasına katılanların \%60'ı erkek, \%40'kadındır. Ayrıca ankete katılanların \%45'i lise mezunu, \%30'u lisans mezunu, \%15'i ilkokul mezunu, \%5'i lisansüstü ve \%5'i de ortaokul mezunudur. Çalışmaya katılanların \%75'i parka yürüyerek ulaşmakta ve geri kalanı ise özel araç veya toplu taşıt araçlarıyla alana ulaşmışlardır. Ankete katılan ziyaretçilerin akıllarında kalan öge en yüksek oranla (\%85) deniz manzarası olmuştur. Çalışan ziyaretçilerin parkta zaman geçirdikleri saat aralıkları 17:00-22:00, çalışmayan veya emeklilerin ise saat 12:00-17:00 olduğu görülmüştür. Sabah saatlerinde ve gece geç saatlerde ise ziyaretçiler parkı tercih etmemektedir. Parkın en fazla kullanılan bölümü kafelerdir. Daha sonra ise çardaklar ve banklar gelmektedir. Ziyaretçilerin amacı en fazla dinlenme olup haftada birkaç kez gelenlerin oranı daha fazladır. Ankete katılan ziyaretçilerin $\% 50$ si etkinlik ve aktivitelerin eksik olduğunu belirtmiş, $\% 40$ 'ı ise temel ihtiyaçların (tuvalet, çeşme vs.) eksik olduğunu söylemiş̧ir. Parkın etrafında fazla yol olmaması ve nüfusun az olması nedeniyle katılımcılar parkta fazla rahatsız edici gürültünün olmadığını belirtmişlerdir. Sadece $\% 25$ 'lik bir kısmı araçların gürültüsünden rahatsız olduğunu söylemiştir.

\section{SONUÇ:}

Kentlerde açık alanların gerekliliği gün geçtikçe artmaktadır. Açık alanlarda yaşam koşullarını insanların farklı ihtiyaçlarını karşılayacak şekilde iyileştirmek gerekmektedir. Fakat tasarımcıların birçoğu tasarladıkları mekanlar kullanıma açıldıktan sonra mekanların kullanım sonrası değerlendirilmesi konusuna gerekli önemi vermeyerek KSD yönteminin önemini göz ardı etmektedirler. $\mathrm{Bu}$ nedenle tasarımcıların tasarladıkları mekanların eksiklerini görmemesinden kaynaklı olarak kullanıma açılan alanın zayıf yönlerinin iyileştirilmemesi ve tasarımcının gelecek projelerde aynı hataları tekrarlama potansiyeli yüksektir.

Bu çalışmada Filyos Sahil Parkın durumu ve eksikleri KSD metodu kullanılarak alana ait veriler elde edilmiştir. Bu çalışmada gözlem çalışmasından ve anketlerden elde edilen sonuçların paralellik gösterdiği görülmüştür ve elde edilen sonuçlara göre; park, yeşil alan olduğundan doku olarak çevresinden farklılaşmaktadır. Alana ulaşım yaya veya özel araçla mümkündür ancak toplu taşıma ile ulaşım yapılmamaktadır. Park, deniz kenarında bulunduğundan büyük ölçüde alana gelen yayalar tarafından dinlenmek amacıyla kullanılmaktadır. Ancak öğle saatlerinde daha aktif kullanılmakta, akşam saatlerinde park içerisindeki birkaç küçük kafe dışında pek kullanılmamaktadır. Ankete katılan ziyaretçilerin akıllarında kalan öge en yüksek oranla deniz manzarası olmuştur. Parkın denizin kıyısında olması çekiciliğini arttırmıştır. Sabah saatlerinde ve gece geç saatlerde ziyaretçiler parkı tercih etmemektedir. Bu da parkın güvenlik 
açısından sorun oluşturuyor olabileceğini göstermektedir. Parkın etrafında fazla yol olmaması ve nüfusun az olması nedeniyle katılımcılar parkta fazla rahatsız edici gürültünün olmadığını belirtmiş̧lerdir. Park tarihi Filyos Kalesinin eteğinde kuruludur fakat tarihi dokuyla ilişkisi çok zayıftır ayrıca parkta tabelalar ve yönlendirme tabelaları yoktur.

Çalışmanın sonuçlarına göre çalışma alanının yeniden düzeltilmesi için bazı öneriler açıklanmıştır; alana ulaşım konusu ele alınmalı ve gelmek isteyenlere toplu ulaşım araçları gibi bazı ulaşım seçenekleri sağlanmalıdır. Gelen ziyaretçilere alanın yanında bulunan tarihi eserin tanıtımı yapılmalıdır. Bu girişte yapılan bilgilendirme panosu veya alanda konulan bir bilgi merkezi aracılığıyla sağlanabilir. Parkta kullanım çeşitliği az olması için kullanıcı özellikle sabah ve öğlen saatlerinde az olmuştur. Bu doğrultuda tüm yaş gruplarını göz önüne alınarak yeniden farklı aktivite imkanları planlanmalıdır. Alanda yönlendirme ve bilgilendirme tabelaları yerleştirmelidir.

\section{Etik Standart ile Uyumluluk}

Çıkar Çatışması: Yazarlar herhangi bir çıkar çatışmasının olmadığını beyan eder.

Etik Kurul İzni: Bu çalışma için etik kurul iznine gerek yoktur.

Finansal Destek: Yoktur.

Teşekkür: Yoktur.

\section{KAYNAKÇA:}

Akad, S. (2007), Kentsel Açık Alanlarda Kullanım Sonrası Değerlendirme: İzmir Sahil Bantları Örneği Üzerine Ampirik Bir Çalışma, Yüksek Lisans Tezi, Fen Bilimleri Enstitüsü, Dokuz Eylül Üniversitesi, İzmir.

Erikci Çelik, S. N., Ve Zorer Gedik, G. (2019). "Yapı Kabuğu Performansının Yenilikçi Bir Tasarım Kapsamında Değerlendirilmesi: Yüzeyden Isıtma Soğutma Sistemli Modüler Hibrid Duvar Örneği-İstanbul”. Megaron, 14(4).

Evrim, T., (2010), Kullanım Sonrası Değerlendirme (KSD) Yönteminin YTÜ Kimya ve Metalurji Fakültesi Binası Örneğinde İncelenmesi, YTÜ Fen Bilimleri Enstitüsü, İstanbul.

Karagenç, O., (2002). Toplu Konut Alanlarında Simgesel Performansa Yönelik Kullanım Sonrası Değerlendirme Modeli, Doktora Tezi, İTÜ Fen Bilimleri Enstitüsü, İstanbul.

Kılıç, A. (2001). Kentsel açık alanların kullanıcılar tarafından değerlendirilmesi. Yüksek Lisans Tezi, Fen Bilimleri Enstitüsü, İstanbul Teknik Üniversitesi, İstanbul.

Kuyucu, F. ve Vatan, M. (2017). "Kullanım sonrası değerlendirme yöntemi: Gaziantep Hasan Kalyoncu Üniversitesi Öğrenci Yurtları Örneği”. İstanbul Aydın Üniversitesi Dergisi, 9 (1), 41-61.

McKenzie, T. L., Cohen, D. A., Sehgal, A., Williamson, S., ve Golinelli, D., (2006). "System For Observing Play And Leisure Activity In Communities (SOPARC): Reliability And Feasibility Measures", Journal of Physical Activity and Health, 3(1), 208-222.

Onat, E., ve Dinç, P., (1998). “Tasarlanmış Çevrelerin Kullanım Süreçlerinde Değerlendirilmesi”, Yapı Dergisi, İstanbul, 201.

Preiser, W. F., White, E., ve Rabinowitz, H. (2015). Post-Occupancy Evaluation (Routledge Revivals). Routledge.

Presier, W. and Vischer, C. (2005). Assessing Building Performance, Fist Edition, Elsevier, Oxford.

Pouya, S, Demirel, Ö. ve Demir, S. (2017). Davranış Haritalama. Peyzaj Mimarlığı 6. Kongresi Bildiri kitabı II. cilt, TMMOB Peyzaj Mimarları Odası, 423-437.

Pouya, S. ve Demirel, Ö. (2018). "Positive health effects of the natural environment on children with disability”. Kahramanmaraş Sütçü İmam Üniversitesi Tarım ve Doğa Dergisi, 21(5), 786-799. 
Pouya, S. ve Demirel, Ö. (2019). "Development planning approach for children with orthopaedic disabilities; example of Eymir Lake (Ankara)". FORESTIST, 69(1), 11-21.

Uzgören G. ve Erdönmez, M. E. (2017). "Kamusal Açık Alanlarda Mekan Kalitesi ve Kentsel Mekan Aktiviteleri İlişkisi Üzerine Karşılaştırmalı Bir İnceleme”, Megaron, 12 (1), 41-56.

Zimring, C. M. ve Reizenstein, J. E. (1980). "Post-occupancy evaluation: An overview". Environment and behavior, 12(4), 429-450.

URL 1. https://gecemanya.com/zonguldak(Erişim Tarihi: 08.11.2019).

URL 2. https://www.filyos.bel.tr/ (Erişim Tarihi: 08.11.2019). 